\title{
Deep-sea water displacement from a turbidity current induced by the Super Typhoon Hagibis
}

\author{
Shinsuke Kawagucci ${ }^{\text {Corresp., 1, } 2 \text {, Tetsuya Miwa }}{ }^{2,3}$, Dhugal J Lindsay ${ }^{4,5}$, Eri Ogura ${ }^{4,5}$, Hiroyuki Yamamoto ${ }^{2,6}$, Kenichiro \\ Nishibayashi ${ }^{7}$, Hiroyuki Yokooka ${ }^{7}$, Shotaro Nishi ${ }^{7}$, Ayu Takahashi ${ }^{8}$, Sangkyun Lee ${ }^{8}$ \\ 1 Super-cutting-edge Grand and Advanced Research (SUGAR) Program, Institute for Extra-cutting-edge Science and Technology Avant-garde Research (X- \\ star), Japan Agency for Marine-Earth Science and Technology (JAMSTEC), Yokosuka, Japan \\ 2 Project team for developing innovative technologies for exploration of deep-sea resources, Japan Agency for Marine-Earth Science and Technology \\ (JAMSTEC), Tokyo, Japan \\ 3 Institute for Marine-Earth Exploration and Engineering (MarE3), Japan Agency for Marine-Earth Science and Technology (JAMSTEC), Yokosuka, Japan \\ 4 Institute for Extra-cutting-edge Science and Technology Avant-garde Research (X-star), Advanced Science-Technology Research (ASTER) Program, Japan \\ Agency for Marine-Earth Science and Technology (JAMSTEC), Yokosuka, Japan \\ 5 Graduate School of Nanobioscience, Yokohama City University, Yokohama, Japan \\ 6 Research Institute for Global Change (RIGC), Marine Biodiversity and Environmental Assessment Research Center (BioEnv), Japan Agency for Marine- \\ Earth Science and Technology (JAMSTEC), Yokosuka, Japan \\ 7 Research and Development Partnership for Next Generation Technology of Marine Resources Survey (J-MARES)/ IDEA Consultants, Tokyo, Japan \\ 8 Research and Development Partnership for Next Generation Technology of Marine Resources Survey (J-MARES) / JGI, Inc., Tokyo, Japan \\ Corresponding Author: Shinsuke Kawagucci \\ Email address: kawagucci@jamstec.go.jp
}

Turbidity currents are themain drivers behind the transportation of terrestrial sediments to the deep sea, and turbidite deposits from such currents have been widely used in geological studies. Nevertheless, the contribution of turbidity currents to vertical displacement of seawater has rarely beendiscussed. This is partly because until recently, deep-sea turbidity currents have rarely been observed due to their unpredictable nature, being usually triggered by meteorological or geological events such as typhoons and earthquakes. Here, we report a direct observation of a deep-sea turbidity current using the recently developed Edokko Mark 1 monitoring system deployed in 2019 at a depth of 1,370 m in Suruga Bay, central Japan. A turbidity current occurred two days after its probable cause, the Super Typhoon Hagibis (2019), passed through Suruga Bay causing devastating damage. Over aperiod of 40 hours, we observed increased turbidity with turbulentconditions confirmed by a video camera. The turbidity exhibited two sharp peaks around 3:00 and 11:00 onOctober 14 (Japan Standard Time). The temperature and salinity characteristics during these high turbidity events agreed with independent measurements for shallow water layers in Suruga Bay at the same time, strongly suggesting that the turbidity current caused vertical displacement in the bay's water column by transporting warmer and shallower waters downslope of the canyon. Our results add to the previous few examples thatshow meteorological and geological events may have significant 
contributions in the transportation of shallower seawater to the deep sea. Recent technological developments pertaining to theEdokko Mark 1 and similar devices enable straightforward, long-term monitoring of the deep-seafloor and will contribute to the understanding of similar spontaneous events in the deep ocean. 
1 Deep-sea water displacement from a turbidity current 2 induced by the Super Typhoon Hagibis

3

4 5

\section{Shinsuke KAWAGUCCI ${ }^{1,2}$, Tetsuya MIWA ${ }^{2,3}$, Dhugal LINDSAY ${ }^{4,5}$, Eri OGURA ${ }^{4,5}$, Hiroyuki} YAMAMOTO $^{2,6}$, Ken-ichiro NISHIBAYASHI ${ }^{7}$, Hiroyuki YOKOOKA ${ }^{7}$, Shotaro NISHI ${ }^{7}$, Ayu TAKAHASHI ${ }^{8}$, Sangkyun LEE ${ }^{8}$

${ }^{1}$ Japan Agency for Marine-Earth Science and Technology (JAMSTEC), Institute for Extracutting-edge Science and Technology Avant-garde Research (X-star), Super-cutting-edge Grand and Advanced Research (SUGAR) Program, 2-15 Natsushima-cho, Yokosuka, Japan 2 Japan Agency for Marine-Earth Science and Technology (JAMSTEC), Project team for developing innovative technologies for exploration of deep-sea resources, 2-2-2 Uchisaiwaicho, Tokyo, Japan

${ }^{3}$ Japan Agency for Marine-Earth Science and Technology (JAMSTEC), Institute for MarineEarth Exploration and Engineering (MarE3), MarE3, 2-15 Natsushima-cho, Yokosuka, Japan ${ }^{4}$ Japan Agency for Marine-Earth Science and Technology (JAMSTEC), Institute for Extracutting-edge Science and Technology Avant-garde Research (X-star), Advanced ScienceTechnology Research (ASTER) Program, 2-15 Natsushima-cho, Yokosuka, Japan 5 Yokohama City University, Graduate School of Nanobioscience, 2-22 Seto, Yokohama Japan. ${ }^{6}$ Japan Agency for Marine-Earth Science and Technology (JAMSTEC), Research Institute for Global Change (RIGC), Marine Biodiversity and Environmental Assessment Research Center (BioEnv), 2-15 Natsushima-cho, Yokosuka, Japan ${ }^{7}$ Research and Development Partnership for Next Generation Technology of Marine Resources Survey (J-MARES)/ IDEA Consultants, Inc., 3-15-1 Komazawa, Setagaya-ku, Tokyo, Japan ${ }^{8}$ Research and Development Partnership for Next Generation Technology of Marine Resources Survey (J-MARES) / JGI, Inc., 1-5-21, Otsuka, Bunkyo-ku, Tokyo, Japan

Corresponding Author: Shinsuke KAWAGUCCI ${ }^{1}$ 2-15 Natsushima-cho, Yokosuka, 237-0061, JAPAN

Email address: kawagucci@jamstec.go.jp 


\section{Abstract}

34 Turbidity currents are the main drivers behind the transportation of terrestrial sediments to the deep sea, and turbidite deposits from such currents have been widely used in geological studies. Nevertheless, the contribution of turbidity currents to vertical displacement of seawater has rarely been discussed. This is partly because until recently, deep-sea turbidity currents have rarely been observed due to their unpredictable nature, being usually triggered by meteorological or geological events such as typhoons and earthquakes. Here, we report a direct observation of a deep-sea turbidity current using the recently developed Edokko Mark 1 monitoring system deployed in 2019 at a depth of $1,370 \mathrm{~m}$ in Suruga Bay, central Japan. A turbidity current occurred two days after its probable cause, the Super Typhoon Hagibis (2019), passed through Suruga Bay causing devastating damage. Over a period of 40 hours, we observed increased turbidity with turbulent conditions confirmed by a video camera. The turbidity exhibited two sharp peaks around 3:00 and 11:00 on October 14 (Japan Standard Time). The temperature and salinity characteristics during these high turbidity events agreed with independent measurements for shallow water layers in Suruga Bay at the same time, strongly suggesting that the turbidity current caused vertical displacement in the bay's water column by transporting warmer and shallower waters downslope of the canyon. Our results add to the previous few examples that show meteorological and geological events may have significant contributions in the transportation of shallower seawater to the deep sea. Recent technological developments pertaining to the Edokko Mark 1 and similar devices enable straightforward, long-term monitoring of the deep-seafloor and will contribute to the understanding of similar spontaneous 54 events in the deep ocean. 


\section{Introduction}

57

58

59

60

61

62

63

64

65

66

67

68

69

70

71

72

73

74

75

76

77

78

79

80

81

82

83

84

85

86

87

88

89

90

91

92

93

94

95
Turbidity currents are particle-laden, gravity-driven flows that efficiently transport terrigenous sediment and organic matter, as well as benthic fauna and microplastics, to the deep sea [Meiburg \& Kneller 2010; Sen et al. 2017; Pohl et al. 2020]. The damaging of seafloor fiberoptic cables by turbidity currents causes serious disruption of social activities [Pope et al. 2017]. The sedimentary deposits resulting from turbidity currents are known as turbidites and have been widely used in geological studies [e.g. Piper \& Normark 2009]. For example, dating of the repeated turbidite sequences in the accretionary prism provide decisive evidence for tectonic evolution at the convergent plate boundary [Taira 2001]. Despite these multidimensional interests, direct observation of turbidity currents in the deep sea had been rare until the beginning of this century [Talling et al. 2013] due to their unpredictable nature and the limited accessibility resulting from challenges and ship time costs of deep-sea expeditions although numbers of the observation have increased during the last decade [Xu, 2010; Liu et al., 2012; Khripounoff et al., 2012; Hughes Clarke, 2019; Paull et al., 2018; Wang et al., 2020; Heerema et al., 2020; Hage et al., 2019; Normandeau et al., 2020; Lintern et al., 2016; Simmons et al., 2020].

Limited in situ direct observations provide the only clues to understand the possible impacts of deep-sea turbidity currents. To date, oceanographic CTD sensors deployed on seafloor observatories have revealed seawater temperature increases associated with deep-sea turbidity currents [Khripounoff et al. 2012; Wang et al. 2020]. A deep-sea mooring observatory off Taiwan has repeatedly captured typhoon-triggered turbidity currents and subsequent temperature increases over a period of 3.5 years [Zhang et al. 2018]. Cabled observatories placed on the deep seafloor have also captured turbidity currents triggered by earthquakes, such as at the Kuril subduction zone [Mikada et al. 2006] and off Hatsushima Island in central Japan [Kasaya et al. 2009]. These observations were coupled with temperature increases, suggesting low-density, shallow seawater were transported into deep depths as the interstitial water of turbidity currents, against the density stratification of the water column [Kao et al. 2010]. However, whether or not turbidity currents routinely cause such vertical displacement of seawater remains unclear due to the limited number of observations.

In addition to earthquakes, powerful tropical cyclones can also provide opportunities for the direct observation of deep-sea turbidity currents [e.g. Liu et al. 2012; Pope et al. 2017; Sequeiros et al. 2019]. On October 12 in 2019 (all timestamps in this paper are presented in JST: Japan Standard Time, UTC+9:00), the extremely large Super Typhoon Hagibis (2019) struck the main island of Japan, leading to a total of 86 deaths [Fire and Disaster Management Agency 2019] and the cancellation of three Rugby World Cup matches. Hagibis reached its peak intensity with a minimum atmospheric pressure of $915 \mathrm{hPa}$ over the Philippine Sea on October 7, and passed through Suruga Bay with an atmospheric pressure of $955 \mathrm{hPa}$ at 18:00 on October 12 (Figure 1A) [Japan Meteorological Agency 2019a]. During the passing of Hagibis, a maximum sea-level 
96

97

98

99

100

101

102

103

104

105

106

107

108

109

110

111

112

113

114

115

116

117

118

119

120

121

122

123

124

125

126

127

128

129

130

131

132

133

134

135

departure of $224 \mathrm{~cm}$ and a 24-hour cumulative precipitation of up to $760 \mathrm{~mm}$ per $\mathrm{m}^{2}$ were recorded on the Izu Peninsula on the east coast of Suruga Bay, and a warning for severe flooding was issued for the riverine area until the morning of October 13 [Shizuoka Local Meteorological Office 2019; Takemi and Unuma 2020]. A global seafloor cable-break database analysis demonstrated that tropical cyclones can trigger deep-sea turbidity currents several days after the cyclone's passing [Pope et al. 2017]. We thus attempted a direct observation of the Hagibislinked deep turbidity current in Suruga Bay two days after the passing of Hagibis. Here, we report visual and oceanographic properties of this in situ turbidity current, captured by the freefall-type deep-sea observatory system Edokko Mark 1 (Figure 2).

\section{Materials \& Methods}

The Edokko Mark 1 (Type HSG) is an all-in-one, free-fall, stand-alone deep-sea monitoring system [Miwa et al. 2015, Japan Agency for Marine-Earth Science and Technology 2017], provided by Okamoto Glass Co. Ltd. (https://ogc-jp.com/en/). The Edokko Mark 1 and other similar systems [Gallo et al. 2020; Clare et al. 2020] increase our capability for the observation of deep-sea turbidity currents when typhoons, earthquakes, or tsunamis impact marginal seas.

The Edokko Mark 1 has a main frame with three glass spheres containing the main computer, HD video cameras, 2400-4000 lumen LED lights, transponder, and batteries. The main frame is further equipped with an acoustic releaser for the ballast weight at the base, a floating glass sphere with a radio beacon and flasher at the top, and a $75 \mathrm{~cm}$ long, $50 \mathrm{~cm}$ wide PVC arm for image-based measurements in the front (Figure 2). Edokko Mark 1 is capable of monitoring for up to three months, owing to reduced battery consumption from a programmable long-term monitoring mode allowing intermittent, periodic observations. In this study, Edokko Mark 1's electric system was continuously powered until 15:23 on 14 October, after which it entered a long-term monitoring mode with observations carried out for 1 minute every 30 minutes until shipboard recovery at 10:20 on 16 October. In the set up used in the present study, a CTD profiler (RINKO profiler, JFE Advantech) and a turbidity meter (ASTD2XTU, JFE Advantech Co., Ltd.) were further attached to the main frame at $1.2 \mathrm{~m}$ above the seafloor (Figure 2). The unit of turbidity, FTU (formazine turbidity unit), is defined as $1 \mathrm{FTU}=$ turbidity where $1 \mathrm{mg}$ of formazin is homogeneously suspended in $1 \mathrm{~L}$ of water.

Edokko Mark 1 landed on the seafloor at a depth of 1,370 $\mathrm{m}$ at the mouth of Heda Canyon, in the northeastern region of Suruga Bay $\left(35^{\circ} 59.63^{\prime} \mathrm{N}-138^{\circ} 40.30^{\prime} \mathrm{E}\right)$. The topography of Heda Canyon is characterized by a narrow and winding valley (Figure 1B) that suggests the repeated occurrence of deep-sea turbidity currents in the past [e.g. Azpiroz-Zabala et al. 2017], probably associated with floods from the Heda River located on the Izu Peninsula (Figure 1A). 
136 Still images were extracted from the video recordings at a $1 \mathrm{~Hz}$ frequency using OpenCV (cv2)

137 within a custom-built Python script (https://github.com/dhugallindsay/Image-based-turbidity-

138 flow-detection). Each 1 minute-long recording event contained several seconds at the beginning

139 when the lighting conditions were unstable just after power supply started. Care was taken

140 during the image extraction to set the start and end times to include only the time period for

141 which lights were on and the illumination was stable. A total of 49 images were extracted from

142 each 1-min recording-interval movie (.mpeg) file. The brightness values (0-255) for each color

143 channel (red, green, blue: RGB) were calculated for each and every pixel in the image and the

144 average values for each channel were then combined using the following formula: $\mathrm{L}=$

$145 \mathrm{~B}^{*} 0.114478+\mathrm{G}^{*} 0.586611+\mathrm{R} * 0.298912$, where $\mathrm{L}$ is luminance, according to the International

146 Telecommunication Union standard ITU-R BT.601 [International telecommunication Union

147 2011]. An average luminance value was then calculated for each image by averaging the values

148 for all pixels, and the 49 values for the 49 images were then averaged to calculate the average

149 luminance of each 49 second-long video file.

150

151

152

153

154

155

156

157

158

159

160

161

162

163

164

165

166

167

168

169

170

171

172

173

174

A vertical profile of seawater properties at the deployment location for the Edokko Mark 1 was made using a XCTD profiler (XCTD-4, Tsurumi-Seiki Co., Ltd.). For a comparison to the

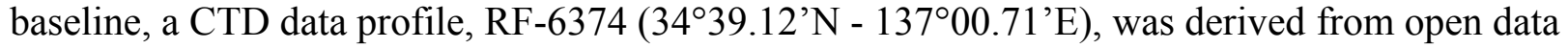
of the 50 -years $137^{\circ} \mathrm{E}$ hydrographic section maintained by the Japan Meteorological Agency [e.g. Oka et al. 2018; Japan Meteorological Agency 2019b].

\section{Results}

The 40 hours of intermittent monitoring with Edokko Mark 1 successfully detected in situ deepsea turbidity currents, probably associated with Typhoon Hagibis. Edokko Mark 1 monitored and recorded the temporal variation of pressure, turbidity, temperature, and salinity (Figure 3), as well as recording video images (Figures 4 and 5) (Supplementary Video File). Oscillation of water pressure at the seafloor corresponded to the tidal cycle, while the approximate mean pressure of 14.05 MPa represents the water depth of 1,370 m where the Edokko Mark 1 was deployed.

Seawater turbidity varied drastically during the observation period (Figure 3). The turbidity stayed at a low level between 1-5 FTU with slight fluctuations until the end of October 14. From 00:55 to 14:55 of October 15, a high turbidity of $>10$ FTU was observed. Eventual spikes over 50 FTU were recorded at 02:55-04:26 and 11:26-11:56, hereafter referred to as the AM3 event and AM11 event, respectively. There was a relatively calmer period between 07:55-10:56. After 14:55 of 15 October, the turbidity again dropped to a low level until the observation ended on October 16. The timings of turbidity increment at 00:55 and the AM3 event corresponded to 
175 those of the low tide, while the turbidity peak of the AM3 event was 3 hours after the last low 176 tide.

177

178

179

180

181

182

183

184

185

186

187

188

189

190

191

192

193

194

195

196

197

198

199

200

201

202

203

204

205

206

207

208

209

210

211

212

213

214

Magnitude of seawater cloudiness in the video images recorded by the camera (Figures 4,5) corresponded well to turbidity levels recorded by the turbidity sensor (Figure 3). At 00:26 on 15 October, the horizontal bars of the Edokko Mark 1's arm, located $30 \mathrm{~cm}$ away from the front of the main body, can be identified (Figure 4A). During the period from 00:56 on 15 October, where strong turbidity was detected, video images confirmed a storm of brownish particles and the bars became indiscernible (Figure 4B, 4C). When the turbidity reached over $100 \mathrm{FTU}$ at 03:56, the video camera blacked out (Figure 4D, 4E), suggesting that the turbidity current struck the camera and light on Edokko Mark 1 after 03:26. Following a relatively calm period (Figure $4 \mathrm{~F}, 4 \mathrm{G}$ ), another black-out situation occurred at 11:26 on 15 October during the AM11 event, when the video camera captured the moment where a turbidity current struck the Edokko Mark 1 (Figures 4H, 5) (Supplementary Video File). After 13:55 on 15 October, when turbidity values were lower than $10 \mathrm{FTU}$, the arm was again identifiable in the video images (Figure 4I, 4J, 4K). The RGB characteristics of the images demonstrated a decrease in blue component when the seawater turbidity increased (Figure 3), indicating the predominance of brownish particles.

Both temperature and salinity, monitored by the Edokko Mark 1, were not stable during the observation period. The temporal variations of temperature and salinity generally yielded a mirror image of each other, even during the temperature peak at 02:55-03:26 on 15th October, in the AM3 event (Figure 3) just before the extreme turbidity over 100 FTU was recorded at 03:55. At the AM11 event, however, only salinity decreased while temperature remained relatively stable. The degree of variation seen in both temperature and salinity were large leading up to the AM11 event, and became more stable after that. Quantitatively, the mean temperature (shown with standard deviation) before the AM1 1 event was $2.78 \pm 0.04{ }^{\circ} \mathrm{C}$ and $2.83 \pm 0.02{ }^{\circ} \mathrm{C}$ after it. The mean salinity, on the other hand, was $34.485 \pm 0.005$ before the AM1 1 event and $34.478 \pm 0.002$ after. Note that the temperature and salinity data during the AM3 and AM11 events were eliminated from the calculation. The decreases in salinity, measured by conductivity using the CTD, were observed during the high turbidity events. These are attributable not only to seawater with lower salinity, but also to increased concentration of suspended particles due to suspended particles being less conductive than seawater [e.g. Wang et al. 2020]. On the other hand, the thermometer is inert to the changes in concentrations of suspended particles and was thus unaffected.

The relationships between the timing of low tide, increase in turbidity and temperature, and video capture of destructive turbidity current differed between AM3 and AM11 events. Before the AM3 event, the lowest tide occurred at midnight and was followed by increase in turbidity at around 01:00 and temperature at around 02:00 (Figure 3), both reaching highest values at the AM3 event. Before the AM11 event which happened at the same time as a low tide, however, no 
215 such signs were detected in the sensors prior to the visual confirmation of the turbidity current,

216 following which the turbidity declined consistently.

217

218 The characteristics of potential temperature and salinity observed by the Edokko Mark 1 during 219 the turbidity current observation generally agreed with those of the ambient water column at the 220 Edokko Mark 1's deployment locality, as observed by the XCTD, as well as the reliable 221 reference data RF-6374 (Figure 6). Slight offsets of potential temperature and salinity

222 characteristics among data from the Edokko Mark 1, XCTD, and RF-6374 are probably due to 223 the insufficient calibration of one or more devices. Consistencies in the trends of potential 224 temperature and salinity variation between the seafloor-deployed Edokko Mark 1 and vertical 225 profilers strongly suggests the displacement of the generally-stratified deep seawater around the 226 Edokko Mark 1. Outside the two events, the potential temperature and salinity values recorded 227 228

229

230

231

232

233 by the Edokko Mark 1 showed slight fluctuation and corresponded to those of the ambient deepseawater at 1,300-1,380 m depth observed by the XCTD, close to the seafloor depth of 1,370 m (Figure 6). Potential temperature and salinity recorded by the Edokko Mark 1 during the AM3 event also followed the trend of the ambient seawater and corresponded to those of seawater approximately $200 \mathrm{~m}$ shallower than Edokko Mark 1's location (Figure 6A-D). Although the properties of the seawater during the AM3 event appears to be attributable to $1 \%$ contribution of

234 surface seawater with a salinity of 31 and temperature of $25^{\circ} \mathrm{C}$ into the bottom water (Figure $6 \mathrm{E}$ ), the direct bimodal mixing between surface and bottom waters is unlikely due to some mixing with seawater at intermediate depths during the downslope transportation being inevitable. On the other hand, the potential temperature and salinity during the AM11 event are too far deviated from those of the water column, suggesting false conductivity signals resulting from the high concentration of suspended particles, as discussed above.

239

240

241

242

243

\section{Discussion}

Turbidity currents can be considered to be the driving force for the vertical stirring of deep-sea water observed in the CTD data during this study, since, in general, low-density shallow seawater cannot sink down to great depths without an external driving force. In support of this, previous observations by cabled observatories have consistently recorded increases of seawater temperature at the seafloor accompanied with turbidity currents [Mikada et al. 2006, Kasaya et al. 2009, Zhang et al. 2018]. Since a turbidity current is a composite of sedimentary particles suspended in a seawater matrix, the density is naturally higher than the density of interstitial water alone and causes the shallow seawater to sink to great depths [Kao et al. 2010]. This mechanism is the most plausible explanation for the current CTD observations by the Edokko Mark 1. As interstitial water density of the typhoon-induced turbidity current during the AM3 event was approximately $0.05 \mathrm{~kg} / \mathrm{m}^{3}$ lower than that during periods outside of the two events

254 (Figure 6D), the turbidity current was able to obtain sufficient density from the suspended 
255 particles. The suspended particles of $>50 \mathrm{FTU}$, corresponding to $0.05 \mathrm{~kg} / \mathrm{m}^{3}$ under the model 256 definition (see Materials \& Methods), can produce sufficient gravity in the whole turbidity 257 current, resulting in the sinking of seawater into the depths of Suruga Bay from at least $200 \mathrm{~m}$ 258 above the seafloor. We would, however, caution that the $1: 1$ model conversion of FTU to $\mathrm{g} / \mathrm{m}^{3}$ is 259 unlikely to be accurate for natural seawater due to variable densities of suspended particles.

260

261

262

263

264

265

266

267

268

269

270

271

272

273

274

275

276

277

278

279

280

281

282

283

284

285

286

287

288

289

290

291

292

293

294

The deep-sea turbidity current observed in this study was probably induced by the recordbreaking Super Typhoon Hagibis (2019). Although the deep-sea turbidity current observed here occurred two days after Hagibis passed over Suruga Bay, it has previously been reported that deep-sea turbidity current occurred even several days after a cyclone passes [Pope et al. 2017]. Although earthquake-induced deep-sea disturbances have been observed to date [Mikada et al. 2006; Kasaya et al., 2009; Kawagucci et al. 2012; Noguchi et al. 2012], no significant earthquake $(\mathrm{M}>1)$ occurred around the Suruga Bay area during Edokko Mark 1's monitoring period. Even though an M5 earthquake occurred at $200 \mathrm{~km}$ east of Suruga Bay at 18:00 on 12 October [JMA 2019], this is both too early and too far away to have been the cause for the turbidity current observed in Suruga Bay by the Edokko Mark 1.

Pin-pointing the trigger mechanism for the deep-sea turbidity current observed herein is challenging, due to the limited availability of information. The turbidity current was observed from a single monitoring location and a single vertical point of the deployed system that could not measure the direction and speed of the in situ current, with no supplemental observation at the river and coast to confirm the exact time and location of the turbidity current release. A known major trigger mechanism for the turbidity current associated with typhoon is river flood [Liu et al. 2012; Lintern et al., 2016; Clare et al., 2016; Hage et al., 2019]. The torrential rainfall from Hagibis on October 12 [Takemi and Unuma 2020] indeed resulted in intensive flooding of rivers in the Izu Peninsula, subsequently flowing into the eastern part of Suruga Bay [Shizuoka Local Meteorological Office 2019]. However, the water level of these rivers returned to normal before the noon of October 13 [Shizuoka Local Meteorological Office 2019], over 24 hours before the turbidity flow event we observed on October 15 . This long lag suggests that the flooding associated with Hagibis itself could not trigger the observed turbidity current. On the other hand, turbidity in the river water may have remained high until October 15 after flooding has ceased, and this hyperpycnal river flow could have continued to supply sufficient suspended particles to trigger the turbidity current. If this combined with low tide at midnight of October 15 to trigger the turbidity current seen during the AM3 event, it would have had a horizontal velocity of $1 \mathrm{~m} / \mathrm{s}$, estimated from the duration of 3 hours and the distance of approximately 11 $\mathrm{km}$ between the Heda river mouth and the location of our Edokko deployment (Figure 1A). This is comparable with the typical velocity seen in turbidity currents [e.g. Khripounoff et al. 2012]. The seawater property demonstrating entrainment with seawater from $200 \mathrm{~m}$ shallower is also not inconsistent with this trigger mechanism when located at a coastal region. Nevertheless, no concrete evidence is available to verify this scenario.

Peer] reviewing PDF | (2020:07:50841:3:0:NEW 30 Oct 2020) 
295

296

297

298

299

300

301

302

303

304

305

306

307

308

309

310

311

312

313

314

315

316

317

318

319

320

321

322

323

324

325

326

327

328

329

330

331

332

333

Another possible trigger for the turbidity current observed is submarine slope failure. It has previously been reported that the rapid accumulation of seafloor sediment associated with tropical cyclones can eventually cause submarine slope failure, resulting in the runoff of a deepsea turbidity current, even several days after a cyclone passes [Pope et al. 2017]. The torrent of flooding, muddy streams in the forest-rich Izu Peninsula up until the noon of October 13 delivered an unusually large amount of terrestrial soil into the seafloor of Suruga Bay, and a part of this accumulation may be further transported into the deep sea before the start of our observation on October 14. Such unconsolidated sediments could serve as precursors of the turbidity current observed on October 15 . Particularly, the turbidity current at the AM11 event which occurred synchronously at low tide without changes in seawater properties would have occurred locally, possibly triggered by a local slope failure around the Edokko Mark 1, rather than being directly triggered by turbid waters from the river.

\section{Conclusions}

We successfully recorded a deep-sea turbidity current probably induced by the Super Typhoon Hagibis and vertical stirring of deep-sea water due to this turbidity current, based on observations by the easy-to-use, autonomous monitoring system Edokko Mark 1. These spontaneous events are difficult to observe without in situ long-term monitoring, and this capacity will help illuminate the diverse forms and mechanisms of turbidity currents in the deep ocean.

\section{Acknowledgements}

Authors are grateful to Drs. Chong CHEN, Kazuya KITADA, Satoshi OSAFUNE, and Shiro MATSUGAURA for supporting cruise operation, data processing, and manuscript editing. This work was conducted as a part of Cross-ministerial Strategic Innovation Promotion Program (SIP) "Innovative Technology for Exploration of Deep-Sea Resources" (Lead agency: JAMSTEC). Authors deeply appreciate the cooperation of Pacific Islands' members who joined the capacity building cruise of SIP.

\section{References}

Azpiroz-Zabala M., Cartigny M. J. B., Talling P. J., Parsons D. R., Sumner E. J., Clare M. A., Simmons S. M., Cooper C. and Pope E. L. (2017) Newly recognized turbidity current structure can explain prolonged flushing of submarine canyons. Science Advances 3, e1700200.

PeerJ reviewing PDF | (2020:07:50841:3:0:NEW 30 Oct 2020) 
334 Clare M. A., Hughes Clarke J. E., Talling P. J., Cartigny M. J. B. and Pratomo D. G. (2016)

335

336

337

338

339

340

341

342

343

344

345

346

347

348

349

350

351

352

353

354

355

356

357

358

359

360

361

362

363

364

365

366

367

368

369

370

371

372

373

Preconditioning and triggering of offshore slope failures and turbidity currents revealed by most detailed monitoring yet at a fjord-head delta. Earth and Planetary Science Letters 450, 208-220.

Clare M., Lintern D. G., Rosenberger K., Hughes Clarke J. E., Paull C., Gwiazda R., Cartigny M. J. B., Talling P. J., Perara D., Xu J., Parsons D., Jacinto R. S. and Apprioual R. (2020) Lessons learned from the monitoring of turbidity currents and guidance for future platform designs. Geological Society, London, Special Publications 500, 605-634.

Gallo, N. D., Hardy, K., Wegner, N. C., Nicoll, A., Yang, H., and Levin, L. A.: Characterizing deep-water oxygen variability and seafloor community responses using a novel autonomous lander, Biogeosciences Discuss., https://doi.org/10.5194/bg-2020-75, in review, 2020.

Hage S., Cartigny M. J. B., Sumner E. J., Clare M. A., Hughes Clarke J. E., Talling P. J., Lintern D. G., Simmons S. M., Silva Jacinto R., Vellinga A. J., Allin J. R., Azpiroz-Zabala M., Gales J. A., Hizzett J. L., Hunt J. E., Mozzato A., Parsons D. R., Pope E. L., Stacey C. D., Symons W. O., Vardy M. E. and Watts C. (2019) Direct Monitoring Reveals Initiation of Turbidity Currents From Extremely Dilute River Plumes. Geophys. Res. Lett. 46, 11310-11320.

J., Talling P. J., Cartigny M. J., Paull C. K., Bailey L., Simmons S. M., Parsons D. R., Clare M. A., Gwiazda R., Lundsten E., Anderson K., Maier K. L., Xu J. P., Sumner E. J., Rosenberger K., Gales J., McGann M., Carter L. and Pope E. (2020) What determines the downstream evolution of turbidity currents? Earth and Planetary Science Letters 532, 116023-11.

Hughes Clarke J. E. H. (2019) First wide-angle view of channelized turbidity currents links migrating cyclic steps to flow characteristics. Nature Communications, 1-13.

International Telecommunication Union (2011) Recommendation ITU-R BT.601-7 (Available online at https://www.itu.int/dms_pubrec/itu-r/rec/bt/R-REC-BT.601-7-201103-I!!PDF-E.pdf. accessed 30 June 2020).

Japan Agency for Marine-Earth Science and Technology (2017) JAMSTEC SIP Protocol Series 4: Acquisition of long-term monitoring images near the deep seafloor by Edokko Mark I.

(Available online at https://www.oceanbestpractices.net/handle/11329/359, accessed 30 June 2020)

Japan Meteorological Agency (2019a) A preliminary report on heavy rainfalls and strong winds by Typhoon Hagibis (2019). (in japanese) (Available online at https://www.data.jma.go.jp/obd/stats/data/bosai/report/2019/20191012/20191012.html, accessed 30 June 2020).

PeerJ reviewing PDF | (2020:07:50841:3:0:NEW 30 Oct 2020) 
374

375

376

377

378

379

380

381

382

383

384

385

386

387

388

389

390

391

392

393

394

395

396

397

398

399

400

401

402

403

404

405

406

407

408

409

410

411

412
Japan Meteorological Agency (2019b) Data of Oceanographic and Marine Meteorological Observation, (Available online at http://www.data.jma.go.jp/gmd/kaiyou/db/vessel_obs/datareport/html/ship/ship_e.php, accessed 30 June 2020).

Kao S. J., Dai M., Selvaraj K., Zhai W., Cai P., Chen S. N., Yang J. Y. T., Liu J. T., Liu C. C. and Syvitski J. P. M. (2010) Cyclone-driven deep-sea injection of freshwater and heat by hyperpycnal flow in the subtropics. Geophys. Res. Lett. 37, L21702.

Kasaya T., Mitsuzawa K., Goto T.-N., Iwase R., Sayanagi K., Araki E., Asakawa K., Mikada H., Watanabe T., Takahashi I. and Nagao T. (2009) Trial of Multidisciplinary Observation at an Expandable Sub-Marine Cabled Station "Off-Hatsushima Island Observatory” in Sagami Bay, Japan. Sensors 9, 9241-9254.

Kawagucci S., Yoshida Y. T., Noguchi T., Honda M. C., Uchida H., Ishibashi H., Nakagawa F., Tsunogai U., Okamura K., Takaki Y., Nunoura T., Miyazaki J., Hirai M., Lin W., Kitazato H. and Takai K. (2012) Disturbance of deep-sea environments induced by the M9.0 Tohoku Earthquake. Scientific Reports 2, 270.

Khripounoff A., Crassous P., Bue Lo N., Dennielou B. and Silva Jacinto R. (2012) Different types of sediment gravity flows detected in the Var submarine canyon (northwestern Mediterranean Sea). PROGRESS IN OCEANOGRAPHY 106, 138-153.

Lintern D. G., Hill P. R. and Stacey C. (2016) Powerful unconfined turbidity current captured by cabled observatory on the Fraser River delta slope, British Columbia, Canada ed. P. Talling. Sedimentology 63, 1041-1064.

Liu J. T., Wang Y.-H., Yang R. J., Hsu R. T., Kao S.-J., Lin H.-L. and Kuo F. H. (2012) Cyclone-induced hyperpycnal turbidity currents in a submarine canyon. J. Geophys. Res. 117, C04033, doi:10.1029/2011JC007630.

Meiburg E. and Kneller B. (2010) Turbidity Currents and Their Deposits. Annu. Rev. Fluid Mech. 42, 135-156.

Mikada H., Mitsuzawa K., Matsumoto H., Watanabe T., Morita S., Otsuka R., Sugioka H., Baba T., Araki E. and Suyehiro K. (2006) New discoveries in dynamics of an M8 earthquakephenomena and their implications from the 2003 Tokachi-oki earthquake using a long term monitoring cabled observatory. Tectonophysics 426, 95-105.

Peer] reviewing PDF | (2020:07:50841:3:0:NEW 30 Oct 2020) 
413 Miwa, T., Y. Iino, T. Tsuchiya, M. Matsuura, H. Takahashi, M. Katsuragawa, T. Fukuba, Y.

414 Furushima, T. Fukuhara, T. Fukushima, and H. Yamamoto. 2016. Underwater Observatory

415 Lander for the Seafloor Ecosystem Monitoring using a Video System. Pages 333-336 in Techno-

416 Ocean. IEEE, Kobe.

417

418 Noguchi T., Tanikawa W., Hirose T., Lin W., Kawagucci S., Yoshida-Takashima Y., Honda M.

419 C., Takai K., Kitazato H. and Okamura K. (2012) Dynamic process of turbidity generation

420 triggered by the 2011 Tohoku-Oki earthquake. Geochem. Geophys. Geosyst. 13, Q11003.

421

422

Normandeau A., Dietrich P., Hughes Clarke J., Van Wychen W., Lajeunesse P., Burgess D. and

423

Ghienne J. F. (2019) Retreat Pattern of Glaciers Controls the Occurrence of Turbidity Currents

424 on High-Latitude Fjord Deltas (Eastern Baffin Island). J. Geophys. Res. Earth Surf. 124, 1559-

425 1571.

426

427

Oguri K., Kawamura K., Sakaguchi A., Toyofuku T., Kasaya T., Murayama M., Fujikura K.,

Glud R. N. and Kitazato H. (2013) Hadal disturbance in the Japan Trench induced by the 2011

429

Tohoku-Oki Earthquake. Scientific Reports 3, 1240-6.

430

431

Oka E., Ishii M., Nakano T., Suga T., Kouketsu S., Miyamoto M., Nakano H., Qiu B., Sugimoto

S. and Takatani Y. (2018) Fifty years of the $137^{\circ}$ E repeat hydrographic section in the western

North Pacific Ocean. Journal of Oceanography 74, 115-145.

434

Paull C. K., Talling P. J., Maier K. L., Parsons D., Xu J., Caress D. W., Gwiazda R., Lundsten E.

436

437

438

439

440

441

442

443

444

445

446

447

448

449

450

451

452
M., Anderson K., Barry J. P., Chaffey M., O’Reilly T., Rosenberger K. J., Gales J. A., Kieft B.,

McGann M., Simmons S. M., McCann M., Sumner E. J., Clare M. A. and Cartigny M. J. (2018)

Powerful turbidity currents driven by dense basal layers. Nature Communications, 1-9.

Piper D. J. W. and Normark W. R. (2009) Processes That Initiate Turbidity Currents and Their Influence on Turbidites: A Marine Geology Perspective. Journal of Sedimentary Research 79, 347-362.

Pohl F., Eggenhuisen J. T., Kane I. A. and Clare M. A. (2020) Transport and burial of microplastics in deep-marine sediments by turbidity currents. Environ. Sci. Technol. 54, 41804189.

Pope E. L., Talling P. J., Carter L., Clare M. A. and Hunt J. E. (2017) Damaging sediment density flows triggered by tropical cyclones. Earth and Planetary Science Letters 458, 161-169.

Sassa K., He B., Miyagi T., Strasser M., Konagai K., Ostric M., Setiawan H., Takara K., Nagai O., Yamashiki Y. and Tutumi S. (2012) A hypothesis of the Senoumi submarine megaslide in

PeerJ reviewing PDF | (2020:07:50841:3:0:NEW 30 Oct 2020) 
453 Suruga Bay in Japan - based on the undrained dynamic-loading ring shear tests and computer

454 simulation. Landslides 9, 439-455.

455

456

457

458

459

460

461

462

463

464

465

466

467

468

469

470

471

472

473

474

475

476

477

478

479

480

481

482

483

484

485

486

487

488

489

490

491

492

493

Sen, A., Dennielou, B., Tourolle, J., Arnaubec, A., Rabouille, C., \& Olu, K. (2017). Fauna and habitat types driven by turbidity currents in the lobe complex of the Congo deep-sea fan. Deep Sea Research Part II: Topical Studies in Oceanography, 142, 167-179.

Sequeiros O. E., Pittaluga M. B., Frascati A., Pirmez C., Masson D. G., Weaver P., Crosby A. R., Lazzaro G., Botter G. and Rimmer J. G. (2019) How typhoons trigger turbidity currents in submarine canyons. Scientific Reports, 9, 9220, doi: 10.1038/s41598-019-45615-z.

Shizuoka Local Meteological Office, 2019: A preliminary climatological report on Typhoon \#19, Hagibis (2019). (in Japanese) (Available online at: https://www.jmanet.go.jp/shizuoka/pdf/saigai/sokuhou20191017.pdf, accessed 18 June 2020).

Simmons S. M., Azpiroz Zabala M., Cartigny M. J. B., Clare M. A., Cooper C., Parsons D. R., Pope E. L., Sumner E. J. and Talling P. J. (2020) Novel Acoustic Method Provides First Detailed Measurements of Sediment Concentration Structure Within Submarine Turbidity Currents. J. Geophys. Res. Oceans 125, 1126-24.

Taira A. (2001) Tectonic evolution of the japanese island arc system. Annu. Rev. Earth Planet. Sci. 29, 109-134.

Takemi, T., and T. Unuma, 2020: Environmental factors for the development of heavy rainfall in the eastern part of Japan during Typhoon Hagibis (2019). SOLA, 16, 30-36, doi: $10.2151 /$ sola.2020-006

Talling P. J., Paull C. K. and Piper D. J. W. (2013) How are subaqueous sediment density flows triggered, what is their internal structure and how does it evolve? Direct observations from monitoring of active flows. Earth Science Reviews 125, 244-287.

Wang Z., Xu J., Talling P. J., Cartigny M. J. B., Simmons S. M., Gwiazda R., Paull C. K., Maier K. L. and Parsons D. R. (2020) Direct evidence of a high-concentration basal layer in a submarine turbidity current. Deep-Sea Research Part I 161, 103300.

Xu J.P. (2010) Normalized velocity profiles of field-measured turbidity currents, Geology, 38, 563-566, doi: 10.1130/G30582.1.

Zhang Y., Liu Z., Zhao Y., Colin C., Zhang X., Wang M., Zhao S. and Kneller B. (2018) Longterm in situ observations on typhoon-triggered turbidity currents in the deep sea. Geology 46, $675-678$.

PeerJ reviewing PDF | (2020:07:50841:3:0:NEW 30 Oct 2020) 
494

495 Supplementary File

496

497 Supplementary File 1: KawagucciSupplMovie.mp4

498 Supplementary File 2: data.xlsx 
Figure 1

Topography around (A) Suruga Bay and (B) the Heda Canyon.

Red broken line shows a track of Typhoon Hagibis on 12 October 2019. 

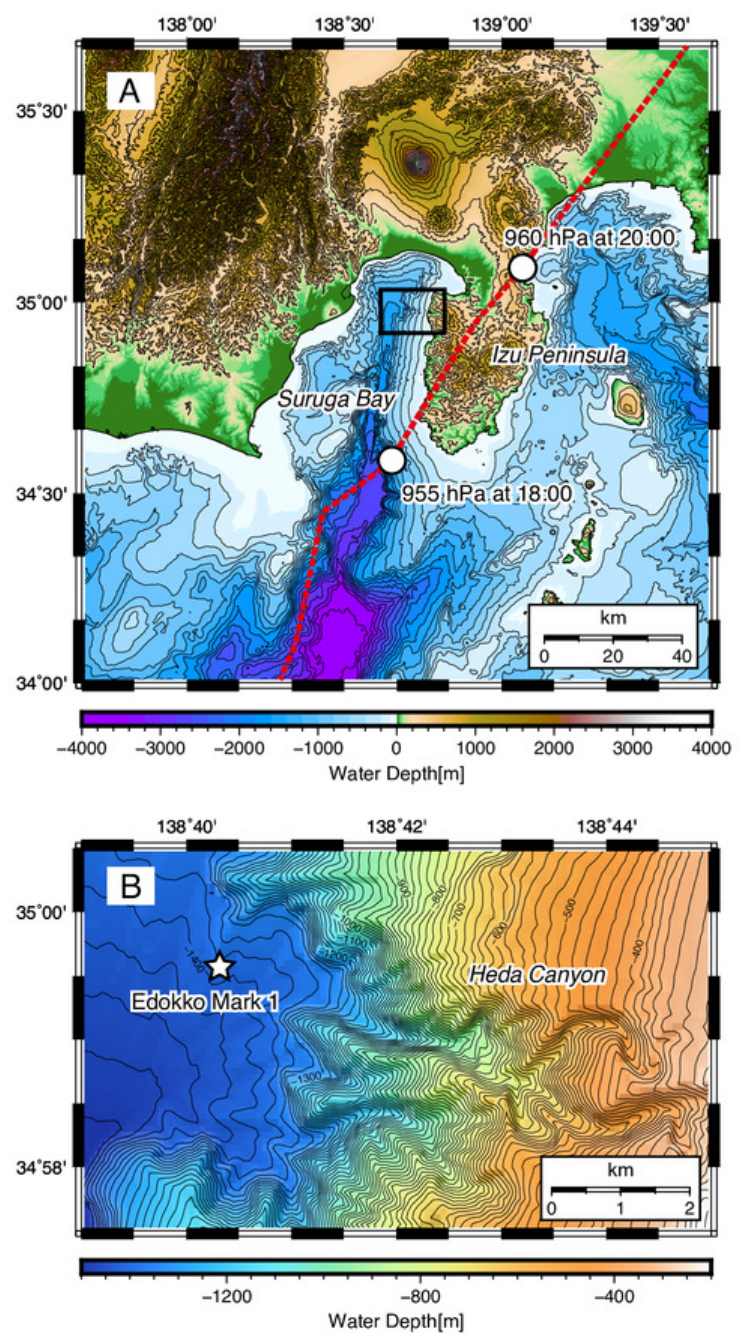
Figure 2

Edokko Mark 1.

(A) Composition and (B) Being deployed.
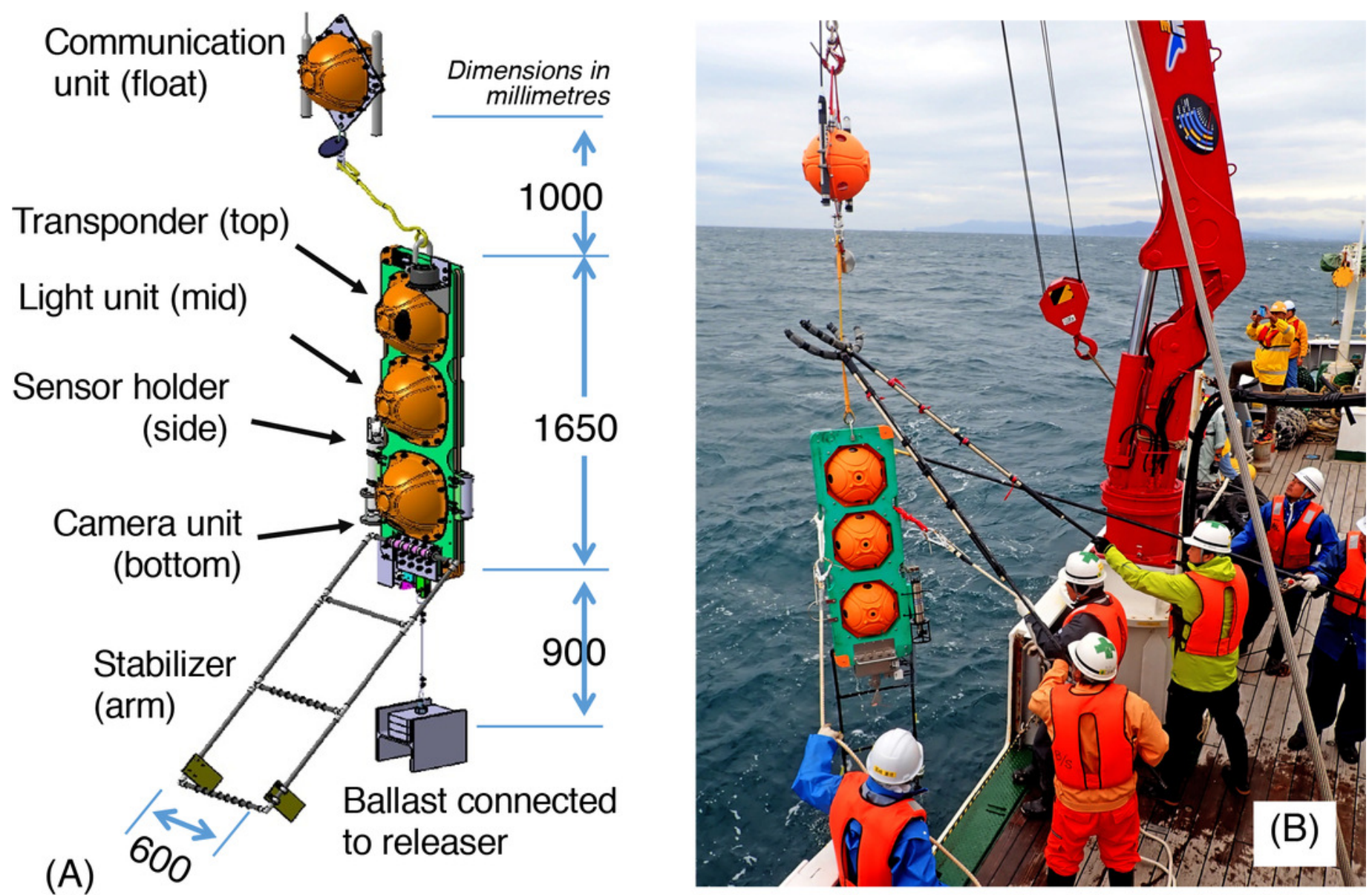
Figure 3

Temporal variation of parameters monitored by Edokko Mark 1.

(A) pressure with surface tide level, (B) turbidity, (C) RGB values of video images, (D) temperature, and (E) salinity. 

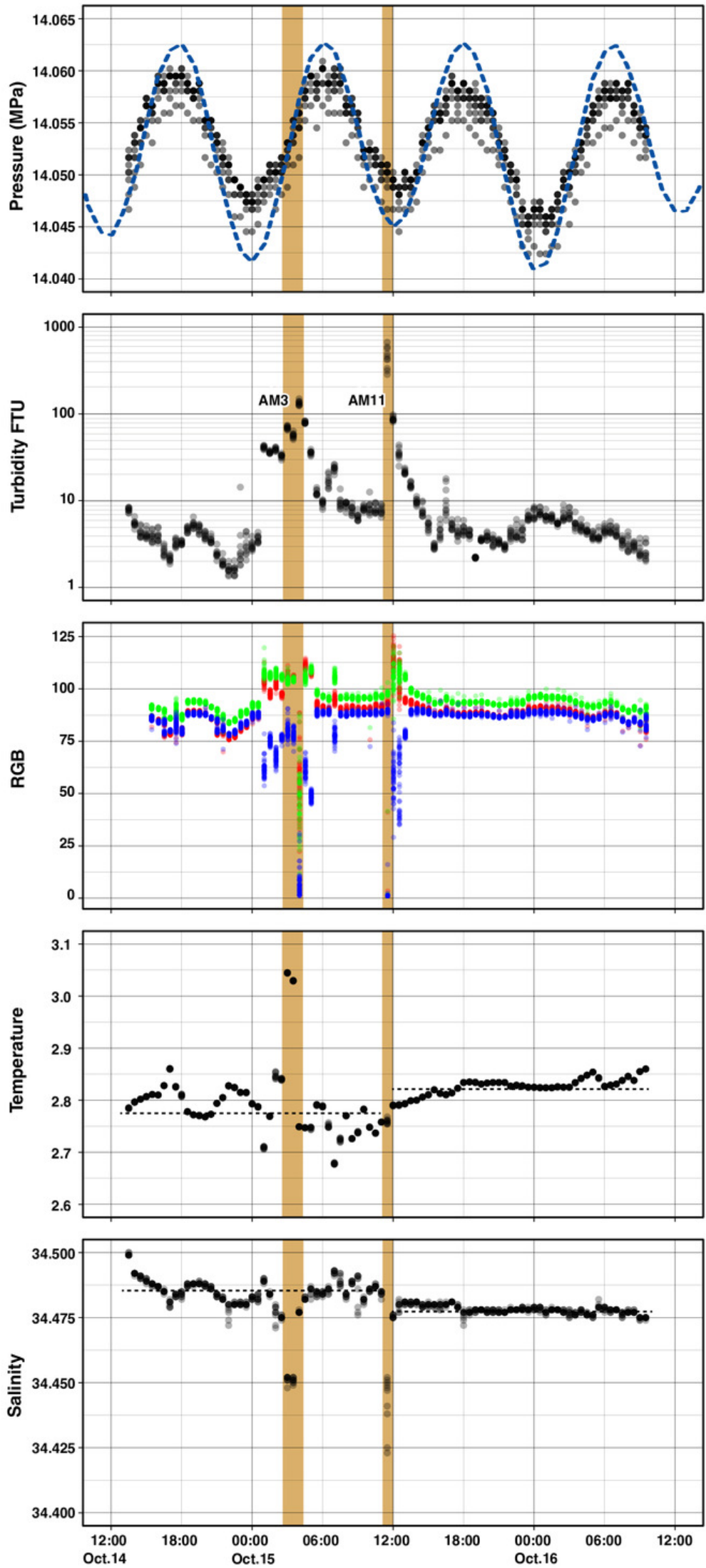
Figure 4

Representative images captured by the video camera on Edokko Mark 1.

Time of extracted images are shown on the frame grabs with panel name (A-J). A black horizontal bar was placed $\sim 50 \mathrm{~cm}$ away from the video camera for distance indication. 


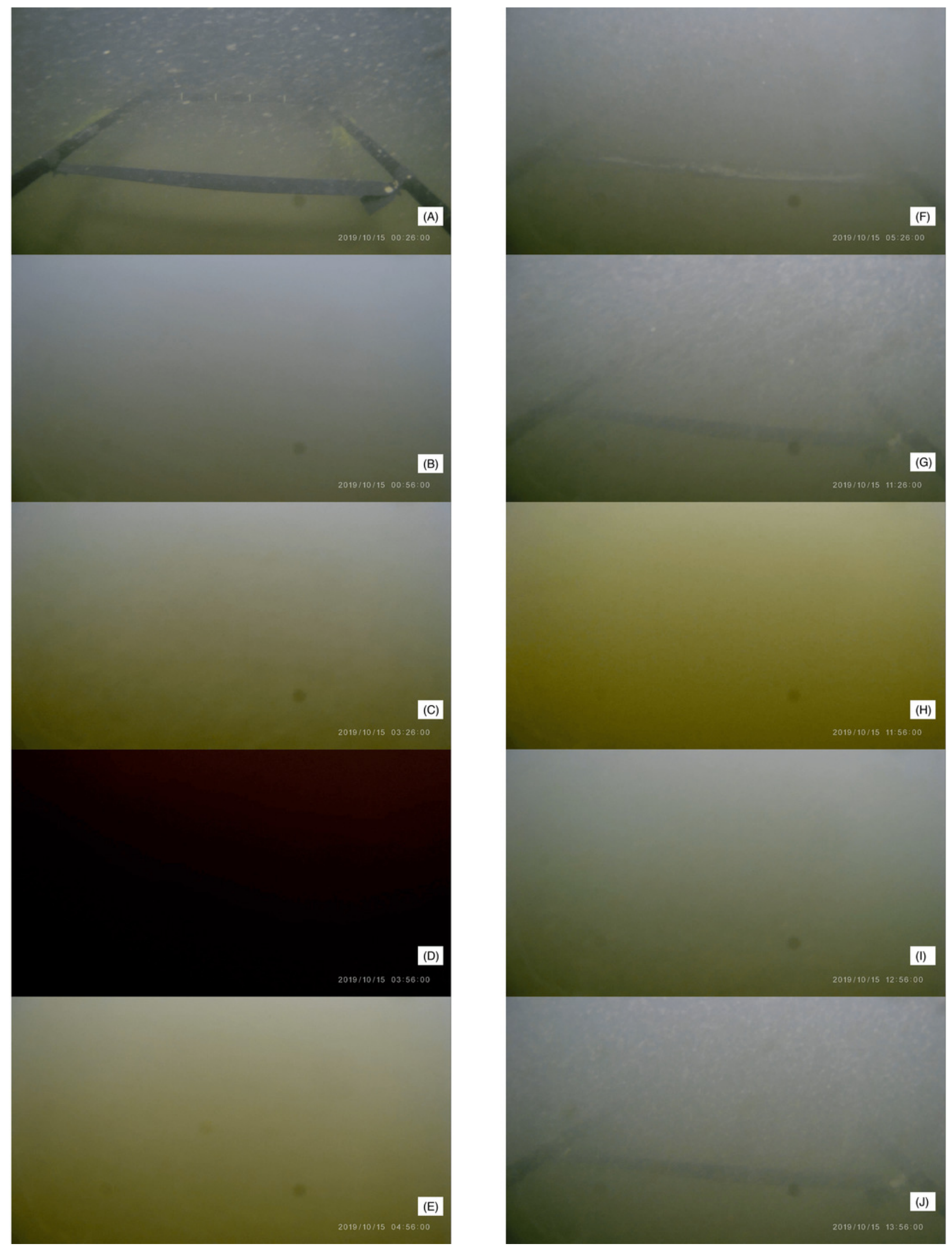


Figure 5

Figure 5: Sequential images during six seconds when a turbidity current struck Edokko Mark 1. 


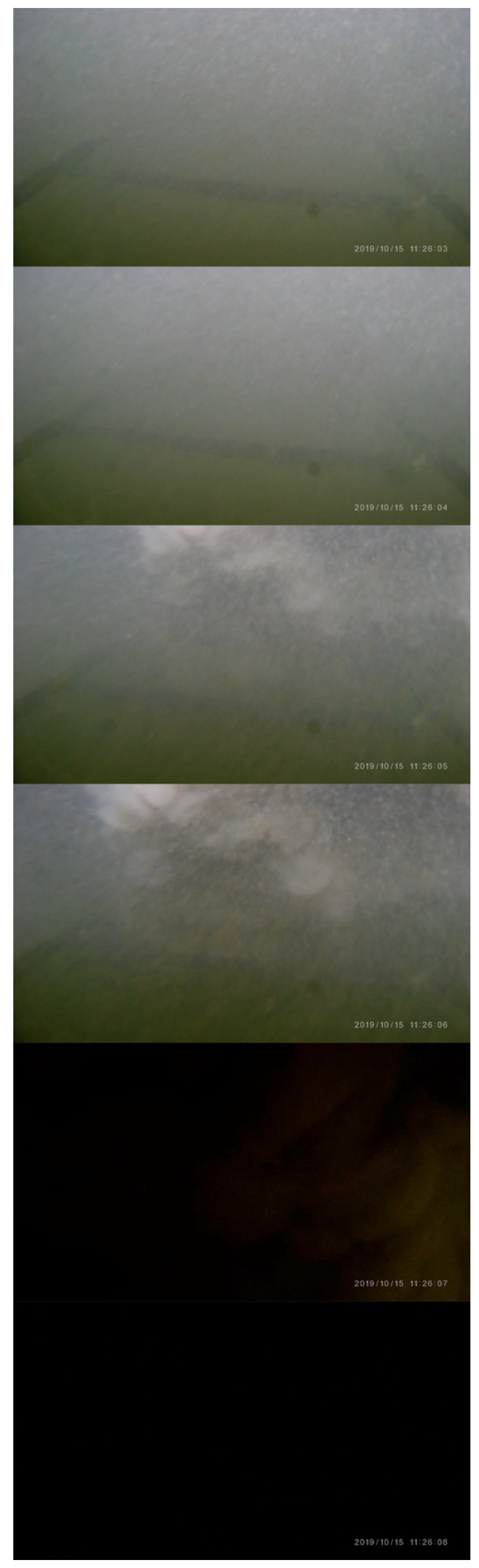

PeerJ reviewing PDF | (2020:07:50841:3:0:NEW 30 Oct 2020) 
Figure 6

Seawater characteristics observed by XCTD (panels A-C), Edokko Mark 1, and the reference RF-6374 (panels D-E). 

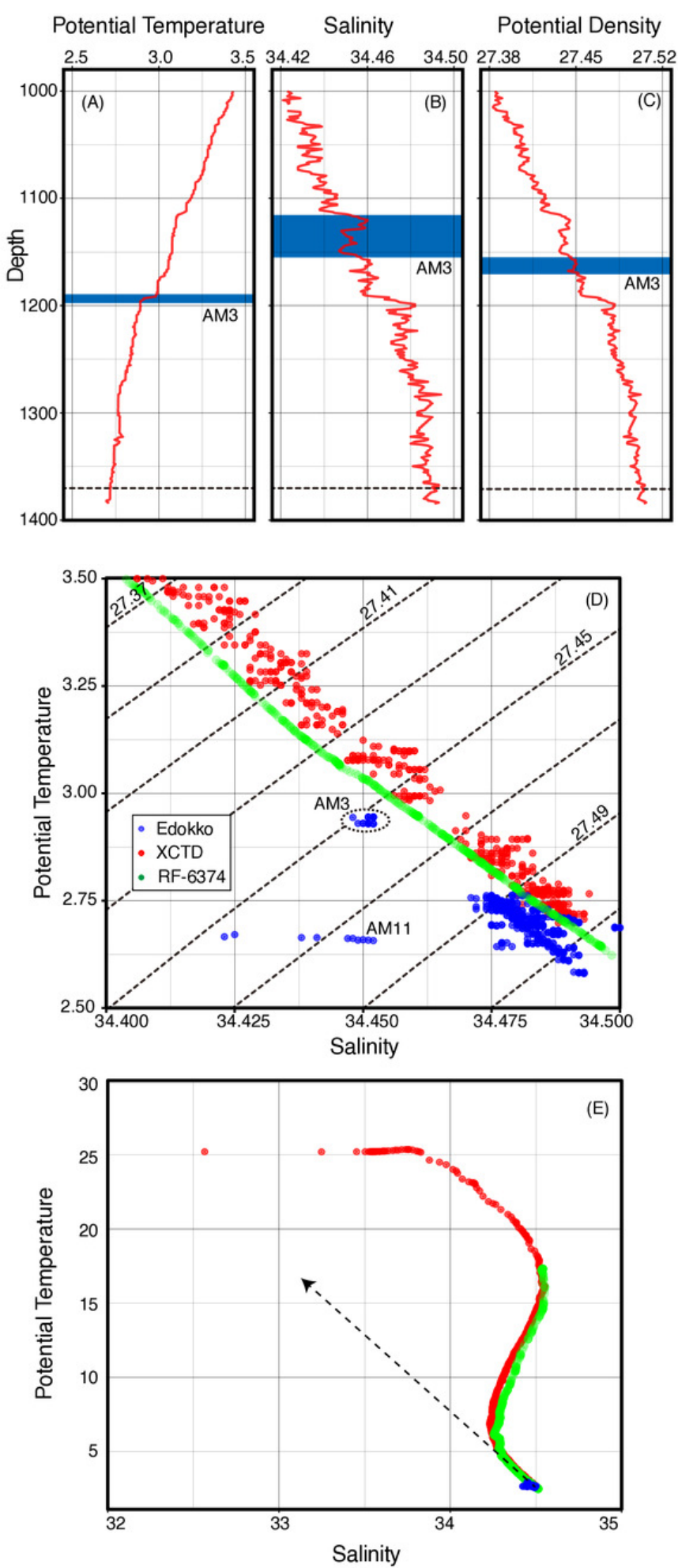